\title{
Os Diferentes Sentidos Atribuídos à Compreensão da Relação da Educação Profissional e Ensino Médio
}

\author{
Janice R. Cardoso Griebeler ${ }^{1}$ \\ Ireni Marilene Zago Figueiredo ${ }^{2}$
}

\begin{abstract}
Resumo
No estudo da Educação Profissional é possível identificar a polissemia dos termos que tratam da relação da Educação Profissional com o Ensino Médio. Este artigo tem como objetivo explicitar os diferentes sentidos atribuídos à compreensão da relação entre Educação Profissional e o Ensino Médio, sendo: a) articulação e integração e b) Educação Profissional Integrada ao Ensino Médio. Trata-se de um estudo teórico com base nos seguintes autores: Garcia (2009), Lima Filho (2002), Ciavatta (2005, 2008), Ramos (2006, 2008), Oliveira (2009), Frigotto (1995), Frigotto, Ciavatta e Ramos (2005a, 2005b), Kuenzer (2000), Frigotto e Ciavatta (2004) e Saviani (2003).
\end{abstract}

Palavras-Chave: Política de Educação Profissional. Articulação e integração. Educação Profissional Integrada ao Ensino Médio.

\section{THE DIFFERENT MEANINGS ASSIGNED BY COMPREHENSION OF THE RELATION BETWEEN PROFESSIONAL EDUCATION AND HIGH SCHOOL}

\begin{abstract}
In the study of Professional Education it is possible to identify the polysemy around the terms that comes to the relation between Professional Education and high school. Thus, the objective of this paper is to point the different meanings assigned by comprehension of the relation between Professional Education and high school, being so: a) articulation and integration; b) full period education and integrated education; c) Professional Education integrated to high school and high school integrated to Professional Education. This is a theoretical study based on the following authors: Garcia (2009), Lima Filho (2002), Ciavatta (2005, 2008), Ramos (2006, 2008), Oliveira (2009), Frigotto (1995), Frigotto, Ciavatta and Ramos (2005a, 2005b), Kuenzer (2000), Frigotto and Ciavatta (2004) and Saviani (2003).
\end{abstract}

Keywords: Professional Education. Articulation and integration. Professional Education integrated to high school.

1 Mestre em Educação pela Universidade do Oeste do Paraná - Unioeste, 2013. Integrante do Grupo de Estudos e Pesquisas em Política Educacional e Social (Geppes). Professora Pedagoga da Rede Estadual do Estado do Paraná. janice-mondrone@ @otmail.com

2 Professora do Colegiado do curso de Pedagogia e do Mestrado em Educação da Unioeste - Universidade Estadual do Oeste do Paraná - Campus de Cascavel - PR. Pesquisadora do Grupo de Estudos e Pesquisas em Política Educacional e Social - Geppes. irenifigueiredo@ hotmail.com 
Criam-se, continuamente, novos termos, novas palavras, seja para expressar novas realidades engendradas pela vida social, seja para projetar, ideologicamente, novas ideias que queremos que se tornem realidade pela aceitação social que possam vir a ter. Mais do que em outras épocas, por meio de novos termos, reiterados pelos meios de comunicação, projeta-se uma história virtual que deve se tornar verdade. [...]. As palavras podem ser ditas, as imagens podem ser mostradas, as coisas acontecem se há vontade política e meios ou recursos, e se elas têm legitimidade perante a opinião pública (Ciavatta, 2005, p. 83-84).

O excerto de Ciavatta (2005) reflete a preocupação com alguns termos com que nos deparamos durante o processo de realização da pesquisa (Griebeler, 2013), uma vez que parece haver um forte neologismo na área da Educação Profissional. A neologia, ${ }^{3}$ de acordo com Alves (1996), na década de 70 torna-se um "conceito polissêmico". Nesse caso, é fundamental tratarmos destes termos polissêmicos para entender o significado atribuído no contexto da reforma da Educação Básica na década de 90, que inclui a Educação Profissional e o Ensino Médio. A utilização dos termos como sinônimos confundem o entendimento ou aquilo que queremos expressar, quando empregados para entender a relação entre a Educação Profissional e o Ensino Médio.

Para Cláudio Gomes Ribeiro (2006), coordenador geral dos cursos Técnicos da Escola Politécnica de Saúde Joaquim Venâncio/Fiocruz,

[...] não existe oposição entre eles, porque não são duas modalidades de educação profissional. Pelo contrário, a modalidade integrada é uma das três (a concomitante e a subseqüente são as demais) formas de articulação entre o ensino médio e a educação profissional técnica de nível médio, conforme regulamenta o Decreto 5.154/2004, nos três Incisos do Par. $1^{\circ}$ do Art. $4^{\circ}$ (2006, p. 6, grifo nosso).

De acordo com Ribeiro, a articulação entre a Educação Profissional e o Ensino Médio pode acontecer de três formas, ou seja, em três modalidades. O coordenador ressalta que o Decreto $n^{\circ} 5.154 / 2004$, no seu artigo $4^{\circ}$, traz que

3 Neologismo é o produto da neologia, processo pelo qual se formam novas unidades lexicais de acordo com as regras de produção do código linguístico utilizado (Guilbert, 1975, p. 31). 
"a Educação Profissional técnica de nível médio será desenvolvida de forma articulada com o Ensino Médio". Logo, a articulação está relacionada com a organização curricular, que, na modalidade integrada, se caracteriza por ter matrícula única em um curso de Educação Profissional, em que o aluno adquire a habilitação profissional e a formação geral em um curso integrado (Ribeiro, conferência de 2006).

Os termos Educação Profissional, integrada e articulação, são encontrados na Lei de Diretrizes e Bases da Educação Nacional nº 9.394/1996, Capítulo III, artigo 39: "A Educação Profissional, integrada às diferentes formas de educação, ao trabalho, à ciência e à tecnologia, conduz ao permanente desenvolvimento de aptidões para a vida produtiva" (Brasil, 2001, grifo nosso). Artigo 40: "A Educação Profissional será desenvolvida em articulação com o ensino regular ou por diferentes estratégias de educação continuada, em instituições especializadas ou no ambiente de trabalho” (Brasil, 2001, grifo nosso).

$\mathrm{O}$ artigo $4^{\circ}$, inciso $1^{\circ}$ do Decreto $\mathrm{n}^{\circ} 5.154 / 2004$ tem por objetivo regulamentar o $\S 2^{\circ}$ do artigo 36 e os artigos 39 a 41 da Lei no 9.394/1996: " $\$ 1^{\circ}$ " A articulação entre a Educação Profissional técnica de nível médio e o Ensino Médio dar-se-á de forma integrada, concomitante ou subseqüente [... ]" (Brasil, 2004, grifo nosso). A forma integrada que o Decreto ${ }^{\circ} 5.154 / 2004$ aponta seria uma forma de articulação, ou seja, a modalidade Educação Profissional de nível médio se dará articulada ao Ensino Médio, podendo ser integrada (matrícula única), concomitante (duas matrículas em um mesmo estabelecimento em cursos diferentes) ou subsequente (matrícula apenas nas disciplinas técnicas), formas de articular a Educação Profissional ao Ensino Médio.

O termo integrado também nos leva a pensar que o seu contrário é a fragmentação e a dissociação. Considerando a proposta de integração da Educação Profissional essa análise estaria correta, pois a integração deve “[...] afirmá-lo na direção da escola unitária e politécnica que supere o dualismo, a fragmentação e o aligeiramento na Educação Profissional para os trabalhadores [...]" (Ciavatta, 2005, p. 5).

Sobre essa questão, Lima Filho (2002, p. 292) enfatiza que 
A terminologia "Educação Profissional" é genérica e abrange vasta gama de processos educativos, de formação e de treinamento em instituições e modalidades variadas. Apesar disso, a opção por empregá-la considerou a sua adoção pela legislação maior (o Capítulo III da LDBEN - da Educação Profissional) e pela legislação complementar. Contudo, a utilização do termo 'educação profissional' em determinadas pesquisas, refere-se especificamente às modalidades de cursos de educação profissional básica, cursos técnicos, de nível médio ou pós-médio, e cursos superiores de tecnologia realizados nas instituições públicas de ensino regular técnico-profissional [...]. O elemento definidor é a vinculação deste tipo de instituição à estrutura regular de ensino. Não desconheço, todavia, que as terminologias educação profissional, ensino profissional, ensino técnico, ensino profissionalizante, formação profissional, capacitação profissional e qualificação profissional sejam utilizadas, indistintamente, para referir-se tanto ao ensino ministrado nas instituições tipificadas anteriormente quanto a quaisquer processos de capacitação da força de trabalho, de jovens e adultos, ministrados por uma ampla variedade de cursos técnicos, de formação ou de treinamento, com natureza, duração e objetivos diferenciados, por instituições as mais diversas, desde as organizações patronais que compõem o Sistema $S$, até instituições privadas ou públicas que atuam em áreas de capacitação e desenvolvimento de recursos humanos, instituições comunitárias ou sindicais, departamentos de recursos humanos de empresas, organizações não governamentais, etc.

Ciavatta (2005) e Ramos (2006) utilizam o termo Ensino Médio integrado ao ensino técnico ou à Educação Profissional e formação integrada. A formação integrada é aquela que "[...] supera o ser humano dividido historicamente pela divisão social do trabalho entre a ação de executar e a ação de pensar, dirigir ou planejar" (Ciavatta, 2005, p. 85). A autora acrescenta que a formação integrada se institui quando "[...] a educação geral torne-se parte inseparável da Educação Profissional em todos os campos onde se dá a preparação para o trabalho: nos processos produtivos, educativos como a formação inicial, ensino técnico e tecnológico” (p. 84), o que não significa preparar para simplesmente executar um trabalho, mas proporcionar a compreensão das dinâmicas socioprodutivas, possibilitando o exercício autônomo e crítico dos trabalhadores. 
A formação integrada sugere tornar íntegro, inteiro, o ser humano dividido pela divisão social do trabalho entre a ação de executar e a ação do pensar, dirigir ou planejar. Trata-se de superar a redução da preparação para o trabalho ao seu aspecto operacional, simplificado, escoimado dos conhecimentos que estão na sua gênese científico-tecnológica e na sua apropriação histórico-social (Ciavatta, 2005, p. 85).

Ao refletir sobre o que é a formação integrada, Ciavatta (2005) pergunta: O que é integrar? A mesma sugere a compreensão do termo, a partir das partes, no seu todo, “[...] como uma totalidade social, resultado das múltiplas mediações históricas que concretizam os processos educativos” (p. 84). Dessa forma, o conceito de formação integrada, segundo a autora, apresenta-se por meio de uma variedade de termos que pretendem expressar a integração.

A ideia de integrar, integração, é muito sedutora. Significa juntar-se, inteirar-se, completar-se e outros significados afins, mas tem também derivados menos atraentes como integrismo, no sentido de adequação total a um sistema, ou integralismo, aplicação total de uma doutrina política com a história política que conhecemos (2008, p. 81-82).

A referência aos termos formação integrada, formação politécnica e educação tecnológica, "[...] buscam responder às necessidades do mundo do trabalho permeado pela presença da ciência e da tecnologia, como forças produtivas, geradoras de valores, fontes de riqueza" (Ciavatta, 2005, p. 85). O termo Educação Profissional tem um sentido mais geral, universal, se comparado ao termo formação profissional. Além disso, o termo Educação Profissional foi uma invenção das políticas dos anos de 1990, e que, historicamente, não tem acompanhado a educação brasileira, que sempre utilizou a expressão formação profissional. Ciavatta (2005) emprega ambos como sinônimos.

Já a ideia de integração entre o Ensino Médio e a Educação Profissional é recente. Seu fundamento “[...] está na busca da superação do tradicional dualismo da sociedade e da educação brasileira e nas lutas pela democracia em defesa da escola pública nos anos de 1980, particularmente, no primeiro projeto da LDB [...]” (Ciavatta, 2005, p. 87), contudo 
É preciso ter claro que a (des) integração entre a formação geral e a formação profissional é um processo político "endêmico" no Brasil. Nunca houve vontade política combinada a meios e poder suficientes para promover o "desengrossamento" necessário de toda a população, de que falava Durmeval Trigueiro Mendes (1983, p. 58) (Ciavatta, 2008, p. 79).

Nesse contexto, Oliveira (2009) vem reafirmar as proposições de Ciavatta (2005) ao destacar a importância da articulação entre a Educação Profissional e o Ensino Médio na perspectiva da integração, e indica que

A articulação entre a formação geral e a formação profissional ainda se coloca como pedagógica e politicamente importante, uma vez que deve haver e vem existindo uma contínua e ininterrupta preocupação por parte daqueles que pesquisam na área de Trabalho e Educação e/ou Ensino Médio de reafirmar o quanto o processo de formação profissional não pode resumir-se apenas à apropriação de saberes práticos e úteis ao mercado de trabalho. Cada vez mais, a luta política por um Ensino Médio que objetive a formação "integral" dos educandos impõe-se como necessária e conseqüente (Oliveira, 2009, p. 53).

Para Ciavatta (2005), a integração entre o Ensino Médio e a Educação Profissional deve buscar os seus fundamentos na formação humana em seu sentido pleno. A formação integrada humanizadora vincula-se à construção de uma sociedade com propósito contrário ao determinado pelo capital.

Como formação humana, a formação integrada busca "garantir ao adolescente", ao jovem e ao adulto trabalhador o direito de uma formação completa para a leitura do mundo e para a atuação como cidadão pertencente a um país, integrado dignamente à sua sociedade política (Ciavatta, 2005, p. 85).

Ramos (2008) relaciona a concepção de Ensino Médio integrado com a concepção de educação unitária, politécnica e de omnilateralidade. Ela defende o projeto de escola unitária que visa a superar a dualidade da formação para o trabalho manual e para o trabalho intelectual.

A concepção da escola unitária expressa o princípio da educação como direito de todos. Uma educação de qualidade, uma educação que possibilite a apropriação dos conhecimentos construídos até então pela humanidade, o 
acesso à cultura, etc. Não uma educação só para o trabalho manual e para os segmentos menos favorecidos, ao lado de uma educação de qualidade e intelectual para o outro grupo (p. 2).

Uma educação que considera os princípios da escola unitária precisa ser politécnica, isto é, "uma educação que, ao propiciar aos sujeitos o acesso aos conhecimentos e à cultura construídos pela humanidade, propicie a realização de escolhas e a construção de caminhos para a produção da vida" (Ramos, 2008, p. 2). A autora se refere ao trabalho como realização e produção humana e também como práxis econômica. Ela propõe as discussões sobre as possibilidades de organização do currículo de Ensino Médio integrado à Educação Profissional, sob os seguintes pressupostos:

[...] a) que conceba o sujeito como ser histórico-social concreto capaz de transformar a realidade em que vive; b) vise à formação humana como síntese de formação básica e formação para o trabalho; c) tenha o trabalho como princípio educativo no sentido de que o trabalho permite concretamente, a compreensão do significado econômico, social, histórico, político e cultural das ciências e das artes; d) seja baseado numa epistemologia que considere a unidade de conhecimentos gerais e conhecimentos específicos e numa metodologia que permita a identificação das especificidades desses conhecimentos quanto à sua historicidade, finalidades e potencialidades; e) seja baseado numa pedagogia que vise à construção conjunta de conhecimentos gerais e específicos no sentido de que os primeiros fundamentam os segundos e esses evidenciam o caráter produtivo concreto dos primeiros; f) seja centrado nos fundamentos das diferentes técnicas que caracterizam o processo de trabalho moderno, tendo como eixos o trabalho, a ciência e a cultura (2005, p. 108-109).

Na análise de Ramos (2008), a educação na forma Integrada deve sustentar-se em um tipo de escola que não seja dual, ao contrário, seja unitária, garantindo a todos o direito ao conhecimento, e em uma educação politécnica, que possibilita o acesso à cultura, à ciência, ao trabalho, por meio de uma educação básica e profissional. Conforme afirma Ciavatta (2005, p. 98): 
O primeiro pressuposto da formação integrada é a existência de um projeto de sociedade no qual, ao mesmo tempo, se enfrente os problemas da realidade brasileira, visando à superação do dualismo de classes e as diversas instâncias responsáveis pela educação (governo federal, secretarias de Educação, direção das escolas e professores) manifestem a vontade política de romper com a redução da formação à simples preparação para o mercado de trabalho.

A politecnia possui um significado bem maior do que seu sentido etimológico, "[...] significa uma educação que possibilita a compreensão dos princípios científico-tecnológicos e históricos da produção moderna, de modo a orientar os estudantes à realização de múltiplas escolhas” (Ramos, 2008, p. 3).

Frigotto (1995) utiliza os termos escola unitária e formação politécnica como sinônimos, acrescentando o termo "omnilateral", originário de Marx, com o significado de "não especializado", contrapondo-se à “unilateral”. É desse modo que frisamos que

[...] As consequiências da revolução operada no processo de trabalho pela manufatura sobre o trabalhador - a atrofia das múltiplas potencialidades humanas levando ao desenvolvimento unilateral dos indivíduos e a perda do significado do trabalho - esses efeitos degradantes sobre as condições de trabalho são expostas em termos enfáticos por Marx ${ }^{4}$ (Bryan, 1992, p. 55-56).

É neste sentido que a compreensão do pensamento e das formulações de Marx apontam para a possibilidade de uma educação para a formação do homem omnilateral, em objeção ao homem unilateral, produto da divisão do trabalho e fragmentação das tarefas que se tornam parciais (Manacorda, 1991, p. 30). Destaca-se, todavia, que os elementos de uma concepção marxista de educação surgiram na década de 1840, em muitas obras de Karl Heinrich Marx (1818-

4 "Enquanto a cooperação simples em geral não modifica o modo de trabalhar do indivíduo, a manufatura o revoluciona inteiramente e se apodera da força individual de trabalho em suas raízes. Deforma o trabalhador monstruosamente, levando-o artificialmente a desenvolver uma habilidade parcial, à custa da repressão de um mundo de instintos e capacidades produtivas, lembrando aquela prática das regiões platinas onde se mata um animal apenas para tirar-lhe a pele ou o sebo. Não só o trabalho é dividido e suas diferentes frações distribuídas entre os indivíduos, mas o próprio indivíduo é mutilado e transformado no aparelho automático de um trabalho parcial..." (K. Marx - K (I), p. 412 apud Bryan, 1992, p. 56). 
1883) e Friedrich Engels (1820-1895). Assim sendo, mesmo tendo a clareza de que Marx "[...] não desenvolveu nenhum tratado sobre educação, nem debateu diretamente com os teóricos da educação" (Favoreto, 2008, p. 21), o debate é pertinente para discussão da relação entre os diferentes sentidos atribuídos à compreensão da relação entre a Educação Profissional e o Ensino Médio.

É nesse sentido que a Escola Unitária teria como princípio possibilitar a formação de sujeitos autônomos e responsáveis a fim de reconstruir as condições dos sujeitos históricos: o direito de acesso à cultura, à ciência e à tecnologia para todos, não de forma estritamente profissionalizante, mas por meio do desenvolvimento de capacidades intelectivas e práticas dos alunos, na perspectiva da dimensão formativa da práxis humana (Frigotto, 1995).

Sobre o conceito de integração, Ramos (2008) relaciona a concepção de formação humana à articulação da Educação Profissional com o Ensino Médio, os quais se complementam em uma proposta de educação na forma Integrada. Os três sentidos para a integração são:

a) Omnilateral: sentido filosófico, expressa uma concepção de formação humana, com base na integração de todas as dimensões da vida no processo formativo.

b) Indissociabilidade entre educação profissional e educação básica: definimos o segundo sentido da integração como as formas de integração do ensino médio com a educação profissional. Voltamo-nos, então, às possibilidades apresentadas pela política nacional, até chegar às escolhas e práticas feitas no âmbito dos sistemas de ensino e das escolas.

c) a integração de conhecimentos gerais e específicos como totalidade: integração entre conhecimentos gerais e específicos conformando uma totalidade curricular [...] (Ramos, 2008, p. 3-14).

Nesse sentido, a autora coloca que a primeira possibilidade e desafio atribuído à integração é expressar uma concepção de formação humana, com base na integração de todas as dimensões da vida no processo formativo, referindo-se à formação omnilateral dos sujeitos, a qual pode ser trabalhada 
tanto no Ensino Médio quanto na Educação Profissional, posto que integram as dimensões do trabalho, da ciência e da cultura, dimensões fundamentais da vida (Ramos, 2008). O trabalho é

[...] realização humana inerente ao ser (sentido ontológico) e como prática econômica (sentido histórico associado ao respectivo modo de produção); a ciência compreendida como os conhecimentos produzidos pela humanidade que possibilita o contraditório avanço produtivo (Ramos, 2008, p. 3).

Dessa forma, a formação profissional estaria estruturada como preparação para o exercício do trabalho considerando que:

1) A centralidade do ensino médio não é o mercado de trabalho, mas sim as necessidades dos sujeitos;

2) O ensino médio integrado deve ser como perspectiva um projeto unitário de ensino médio - que não elide as singularidades dos grupos sociais mas se constitui como síntese do diverso - tendo o trabalho como o primeiro fundamento da educação como prática social;

3) Proporcionar, com o ensino médio integrado, uma formação que possibilite o exercício produtivo não é o mesmo que fazer uma formação profissionalizante, posto que tal participação exige, antes, a compreensão dos fundamentos da vida produtiva em geral;

4) O ensino médio integrado, considerando seus sentidos filosófico, epistemológico e político que estrutura sua base unitária, incorpora também, na perspectiva de um projeto nacional, o diverso (Ramos, 2008, p. 2-26).

O trabalho, a ciência e a cultura são concebidos como elementos integradores, que devem ser compreendidos a partir do trabalho como princípio educativo, o que "não se confunde com o 'aprender fazendo', nem é sinônimo de formar para o exercício do trabalho". Ver o trabalho “[...] como princípio educativo equivale dizer que o ser humano é produtor de sua realidade e, por isto, se apropria dela e pode transformá-la" (Ramos, 2008, p. 4). Logo, a formação na Educação Profissional na forma Integrada não se restringe à preparação exclusiva para o exercício do trabalho, mas proporciona a compreensão das relações socioprodutivas, sendo 
[...] preciso que o ensino médio defina sua identidade como última etapa da educação básica mediante um projeto que, conquanto seja unitário em seus princípios e objetivos, desenvolva possibilidades formativas que contemplem as múltiplas necessidades socioculturais e econômicas dos sujeitos que o constituem - adolescentes, jovens e adultos -, reconhecendo-os não como cidadãos e trabalhadores de um futuro indefinido, mas como sujeitos de direitos no momento em que cursam o ensino médio (Ramos, 2008, p. 5).

Ramos (2008) acrescenta que dispomos de amparo legal para pôr em prática a Educação Profissional articulada ao Ensino Médio na forma Integrada, porém é necessário, ainda, reconhecer o direito ao trabalho para as classes trabalhadoras na perspectiva econômica, o qual atribui a profissionalização dos jovens como uma necessidade. A Educação Profissional, articulada ao Ensino Médio na forma Integrada, revela a preocupação de superar a histórica dualidade que tem marcado a educação em diálogo com a escola desinteressada, já referenciada neste trabalho e objeto da síntese de Ramos (2008).

A Educação Profissional articulada ao Ensino Médio na forma Integrada não é uma política compensatória para aqueles que não teriam acesso ao ensino superior. A profissionalização dos jovens é tanto uma necessidade quanto uma possibilidade para o enfrentamento das contradições econômicas, como "[...] uma condição necessária para se fazer a 'travessia' para uma nova realidade” (Frigotto; Ciavatta; Ramos, 2005a, p. 43). Foi essa “travessia” que o Decreto n 2.208/1997 suspendeu ao não permitir ao Ensino Médio proporcionar a formação técnica, por meio da articulação da Educação Profissional e do Ensino Médio (Frigotto; Ciavatta; Ramos, 2005a, p. 43). Dessa forma, o Decreto ${ }^{\circ}$ 5.154/2004 pretende

[...] reinstaurar um novo ponto de partida para essa travessia, de tal forma que o horizonte do ensino médio seja a consolidação da formação básica unitária e politécnica, centrada no trabalho, na ciência e na cultura, numa relação mediata com a formação profissional específica que se consolida em outros níveis e modalidades de ensino (Frigotto; Ciavatta; Ramos, 2005a, p. 43-44).

Essa condição compreende a dimensão da vida do sujeito, possibilitando aos jovens e adultos se apropriarem de conhecimentos que estruturem a sua inserção na vida produtiva dignamente, garantindo o direito à Educação Básica e possibilitando a formação na Educação Profissional, considerando que 
A forma integrada de oferta do ensino médio com a educação profissional obedece a algumas diretrizes ético-políticas, a saber: integração de conhecimentos gerais e específicos; construção do conhecimento pela mediação do trabalho, da ciência e da cultura; utopia de superar a dominação dos trabalhadores e construir a emancipação - formação de dirigentes. Sob esses princípios, é importante compreender que o ensino médio é a etapa da educação básica em que a relação entre ciência e práticas produtivas se evidencia; e é a etapa biopsicológica e social de seus estudantes em que ocorre o planejamento e a necessidade de inserção no mundo do trabalho, no mundo adulto (Ramos, 2008, p. 14).

A articulação da Educação Profissional com o Ensino Médio na forma Integrada deve levar em conta, ainda, os conhecimentos gerais e específicos em uma totalidade: "não existe essa separação que o positivismo nos fez crer ao longo da história, com base na qual se naturaliza a ideia de que o professor da Educação Básica ministra as teorias gerais, enquanto o professor da formação técnica ministra as suas aplicações" (Ramos, 2008, p. 16).

\begin{abstract}
Assim, queremos dizer que nenhum conhecimento específico é definido como tal se não consideradas as finalidades e o contexto produtivo em que se aplicam. Queremos dizer ainda que, se ensinado exclusivamente como conceito específico, profissionalizante, sem sua vinculação com as teorias gerais do campo científico em que foi formulado, provavelmente, não se conseguirá utilizá-lo em contextos distintos daquele em que foi aprendido (Ramos, 2008, p. 17).
\end{abstract}

Dessa forma, o conhecimento específico é definido a partir das finalidades e do contexto produtivo em que se aplica. A proposta de integração defendida por Ramos (2008) entende a concepção de homem histórico e a realidade como totalidade (historicidade do conhecimento), sendo os pressupostos que fundamentam a Educação Profissional na forma Integrada.

O ensino médio puro não configura identidades dos sujeitos que precisam urgentemente se inserir na vida produtiva. Esses sujeitos conseguiriam emprego? Isto não está dado, pois a educação não garante o emprego. Mas falamos em lutar ativamente, municiado de conhecimentos, de categorias que levem à compreensão da realidade social e a meios de ação profissional. Uma 
formação genérica que não tem significado concreto para os sujeitos é uma formação que os coloca na lógica subordinada. Assim, a defesa do ensino médio integrado não reforça a ideia da empregabilidade (Ramos, 2008, p. 27).

A integração exige que a relação entre os conhecimentos gerais e os específicos seja construída continuamente ao longo da formação, considerando o trabalho no contexto em que é construído, o que justifica "[...] a formação específica para atividades diretamente produtivas" (Ramos, 2008, p. 8). Dessa forma, a sobreposição de disciplinas de formação geral e de formação específica, ao longo de um curso, não é o mesmo que integração, assim como não é o mesmo a adição de um ano de estudos profissionais a três anos de Ensino Médio ou da Educação Profissional. Nessa perspectiva,

[...] trata-se de superar a redução da preparação para o trabalho ao seu aspecto operacional, simplificado, escoimado dos conhecimentos que estão na sua gênese científico-tecnológica e na sua apropriação histórico-social. Como formação humana, o que se busca é garantir ao adolescente, ao jovem e ao adulto trabalhador o direito a uma formação completa para a leitura do mundo e para a atuação como cidadão pertencente a um País, integrado dignamente à sua sociedade política (Brasil, 2007, p. 41).

Para Garcia (2009), a perspectiva de integração proposta pelo Decreto n $5.154 / 04$ constitui a melhor forma para alicerçar no Ensino Médio os conhecimentos científicos e tecnológicos, a fim de construir uma identidade dessa etapa da Educação Básica, em que a educação não seja nem toda propedêutica tampouco apenas profissionalização, posto que

O erro histórico das "mudanças" talvez tenha sido a persistência de uma coisa ou outra. Construir uma educação neste nível de ensino não é apenas uma opção por uma forma ou outra, é a construção de uma educação que possibilite a apropriação dos conhecimentos construídos pela humanidade e o acesso à cultura (p. 63).

A categoria Educação Básica é considerada como responsável por garantir a integração entre os diferentes níveis e modalidades de ensino, por abarcar a formação mínima necessária ao sujeito trabalhador, tomando como ponto de 
partida para a integração o trabalho como princípio educativo. Adotar o trabalho como princípio educativo na sociedade capitalista significa " [...] $a$ construção de políticas que atendam às necessidades dos que vivem do trabalho, isto é possível pela própria contradição, considerados os limites e possibilidades da escola" (Garcia, 2009, p. 64). Nesse sentido

[...] pode-se enfatizar o compromisso da educação profissional com a educação básica, compreendida como um direito social e condição indispensável para a superação da perspectiva direcionada para o simples adestramento e adaptação às demandas ditadas pelo mercado e, portanto pelo capital (Paraná, 2005a, p. 49).

Kuenzer (2000) corrobora tais proposições ao considerar que "[...] a finalidade da escola que unifica cultura e trabalho é a formação de homens desenvolvidos multilateralmente, que articulem a sua capacidade produtiva às capacidades de pensar, de estudar, de dirigir ou de controlar quem dirige" (Kuenzer, 2000, p. 24) uma escola unitária, que propunha inserir os jovens na vida social, após terem adquirido certa maturidade, capacidade intelectual e prática (Garcia, 2009).

O documento Base do MEC da Educação Profissional Técnica de Nível Médio Integrada ao Ensino Médio, publicado em 2007, apresenta elementos importantes para pensarmos a Educação Profissional integrada ao Ensino Médio na forma Integrada. $\mathrm{O}$ documento retoma o debate promovido pela revogação do Decreto no 2.208/1997, segundo o qual a Educação Profissional de nível técnico teria organização curricular própria e independente do Ensino Médio, e pela publicação do Decreto $n^{\circ} 5.154 / 2004$, que apresenta a possibilidade de a Educação Profissional acontecer articulada ao Ensino Médio na forma Integrada.

A apresentação do documento Base do MEC da Educação Profissional Técnica de Nível Médio Integrada ao Ensino Médio apresenta uma explicação sobre a necessidade e a importância da articulação entre a Educação Profissional articulada ao Ensino Médio e sua realização de forma integrada. O documento faz referência às ações realizadas com a finalidade de discutir e viabilizar políticas no sentido da integração, evidenciando a necessidade de ' $[$...] uma ação 
política concreta de explicitação, para as instituições e sistemas de ensino, dos princípios e diretrizes do Ensino Médio integrado à Educação Profissional" (Brasil, 2007, p. 4).

O documento expressa historicamente as ações realizadas a partir de 2003 no sentido da integração. O Ministério da Educação/Setec, em 2003, organizou dois seminários ${ }^{5}$ para debater as questões da integração. O primeiro Seminário Nacional “[...] Ensino Médio: Construção Política”, que ocorreu em Brasília em maio de 2003, [...] "teve como objetivo discutir a realidade do Ensino Médio brasileiro e novas perspectivas na construção de uma política para esse nível de ensino [...]" (Brasil, 2007, p. 6), cujo resultado foi sistematizado no livro: Ensino Médio: Ciência, Cultura e Trabalho. O segundo Seminário Nacional de Educação Profissional Concepções, experiências, problemas e propostas, específico da Educação Profissional e Tecnológica, teve como base de discussão o documento intitulado: Políticas Públicas para a Educação Profissional e Tecnológica. $\mathrm{O}$ resultado dessas discussões foi sistematizado no documento publicado pelo Setec, em 2004, Proposta em discussão: Políticas Públicas para a Educação Profissional e Tecnológica (Brasil, 2007, p. 6). Este documento pretendia

[...] resgatar as concepções e princípios gerais que deverão nortear a educação profissional e tecnológica, baseados no compromisso com a redução das desigualdades sociais, o desenvolvimento socioeconômico, a vinculação à educação básica e a uma escola pública de qualidade (Brasil, 2004, p. 6).

Três minutas do Decreto $\mathrm{N}^{\circ} 5.154 / 2004$ que veio a revogar o Decreto $\mathrm{N}^{\circ} 2.208 / 1997$ foram elaboradas, considerando que

5 Participaram desses Seminários instituições científicas, educadores, pesquisadores, entidades de classe, instituições de ensino, representantes dos Ministérios da Educação e do Trabalho e Emprego e outros órgãos do governo, Sistemas Estaduais de Ensino, Sistema S (Serviço Nacional de Aprendizagem Industrial - Senai; Serviço Social do Comércio - Sesc; Serviço Social da Indústria - Sesi e Serviço Nacional de Aprendizagem do Comércio - Senac). Existem ainda os seguintes: Serviço Nacional de Aprendizagem Rural (Senar); Serviço Nacional de Aprendizagem do Cooperativismo (Sescoop); e Serviço Social de Transporte (Sest) e parlamentares. 
Esse processo manteve-se polêmico, em todos os encontros, debates e audiências realizados com representantes de entidades da sociedade civil e de órgãos governamentais. Todas as contribuições recolhidas nesses momentos levaram a um progressivo amadurecimento do tema que não tomou forma em uma via de mão única, ao contrário, manteve as contradições e disputas teóricas e políticas sinalizadas desde o início do processo, culminando no Decreto n. 5154/04 (Frigotto; Ciavatta; Ramos, 2005a, p. 23).

\section{O documento Base do MEC da Educação Profissional Técnica de Nível} Médio Integrada ao Ensino Médio, destaca que, dentre as concepções defendidas pelos participantes nos Seminários, duas posições de Educação Profissional ficaram evidenciadas: a primeira concepção baseava-se nos princípios do Decreto No 2.208/1997, que, na sua essência, separava a Educação Profissional da Educação Básica e defendia a sua manutenção; e a segunda concepção trazia para o debate os princípios da educação tecnológica e politécnica. Os esforços concentraram-se em superar a divisão entre conhecimentos específicos e gerais, Ensino Médio e Educação Profissional (Brasil, 2007, p. 7), e deslocava ' [...] o foco do mercado de trabalho para a pessoa humana, tendo como dimensões indissociáveis o trabalho, a ciência, a cultura e a tecnologia”, considerando como ' ' [...] necessária e adequada à formação da classe trabalhadora brasileira no sentido de sua autonomia e emancipação" (Brasil, 2007, p. 6-9).

A esse respeito, Frigotto e Ciavatta (2004) elaboraram o documento analítico ${ }^{6}$ sobre as posições manifestadas a respeito de uma possível revogação do Decreto $\mathrm{n}^{\circ} 5.154 / 2004$, evidenciando nesse debate que:

[...] uma primeira posição expressa em três documentos defendia a ideia ou tese de que cabe apenas revogar o Decreto n. 2.208/97 e pautar a elaboração da política de Ensino Médio e Educação Profissional, de uma parte, pelo fato de a LDB em vigor (Lei n. 9.394/96) contemplar as mudanças que estão sendo propostas e, de outra, por se entender que tentar efetivar mudanças por decreto significa dar continuidade ao método impositivo do governo anterior.

6 Trata-se do documento elaborado pelos professores Maria Ciavatta e Gaudêncio Frigotto, discutido e revisto pela equipe da Diretoria de Ensino Médio da Semtec (Frigotto; Ciavatta, 2004). 
Uma segunda posição é expressa, mais diretamente, por um documento que se posiciona pela manutenção do atual Decreto n. 2.208/97 e outros documentos que indiretamente desejariam que as alterações fossem mínimas.

Por fim, uma terceira posição, que consta de um número mais significativo de documentos, direta ou indiretamente partilha da ideia da revogação do Decreto n. 2.208/97 e da promulgação de um novo Decreto. Estes documentos, de abrangência e conteúdo diversos, [...] ofereceram suas sugestões de supressão, melhoria e acréscimos para novo Decreto (Frigotto; Ciavatta; Ramos, 2005a, p. 23-24).

$\mathrm{Na}$ análise das três posições, Frigotto e Ciavatta (2004) constataram que não houve consenso entre elas, sendo o primeiro e o segundo posicionamentos opostos entre si, e a terceira posição, em termos de princípios e concepções, não divergiam da primeira, porém afastavam-se na forma de encaminhamento político. Em relação aos documentos produzidos, os referentes à primeira posição "[...] foram fundamentais no processo tanto de implementação do novo Decreto, quanto para, em médio prazo, a construção de um instrumento legal mais adequado" (Frigotto; Ciavatta; Ramos, 2005a, p. 24).

Para Frigotto, Ciavatta e Ramos (2005a), os Seminários procuraram aprofundar as reflexões sobre as concepções do conhecimento, do trabalho e da cultura, além da elaboração de documentos para a construção da Política do Ensino Médio e da Educação Profissional, que resultou no Decreto n ${ }^{\circ}$ 5.154/2004.

O documento Base do MEC da Educação Profissional Técnica de Nível Médio Integrada ao Ensino Médio ressalta que a perspectiva da formação integral e da articulação entre o Ensino Médio e a Educação Profissional integrada foi perdendo-se gradativamente em razão da correlação de forças existente entre a educação pública e a privada, respeitando que " [...] a revogação do Decreto $N^{\circ}$ 2.208/1997 tornou-se emblemática da disputa e a expressão pontual de uma luta teórica em termos da pertinência político-pedagógica do Ensino Médio integrado à Educação Profissional" (Frigotto; Ciavatta; Ramos, 2005a, p. 26).

A fragmentação aconteceu dentro do próprio Ministério da Educação no processo de reestruturação, ao deixar o Ensino Médio sob a responsabilidade da Secretaria de Educação Básica e a Educação Profissional sob a responsabilidade 
da Secretaria de Educação Média e Tecnológica que, segundo Frigotto, Ciavatta e Ramos (2005a, p. 45), “aponta formalmente o dualismo”. Além disso, algumas medidas tomadas pelo MEC evidenciaram que "[...] a política de integração não seria prioridade e que não estavam claras as concepções das equipes dessas secretarias" (Frigotto; Ciavatta; Ramos, 2005b, p. 1.091).

O que caberia, neste caso, dentro de um fundamento teórico e histórico, seria uma Secretaria de Educação Básica que incluiria, portanto, o ensino médio dentro da concepção tecnológica ou politécnica e uma Secretaria de Educação Profissional stricto sensu. Este poderia ser um avanço teórico e político importante, pois esta última Secretaria teria uma tarefa de articular e ter a prerrogativa de coordenar a enorme dispersão de entidades e iniciativas de educação profissional, articulando-as à educação básica numa estratégica de elevação de escolaridade (Frigotto; Ciavatta; Ramos, 2005a, p. 45).

Para Kuenzer e Garcia (2008, p. 51), o documento Base do MEC da Educação Profissional Técnica de Nível Médio Integrada ao Ensino Médio apresenta um quadro da Educação Profissional e do Ensino Médio e “[...] resgata do primeiro projeto da $L D B$ a perspectiva da politecnia”, posto que

[...] essa retomada produz reflexões importantes quanto à possibilidade material da implementação da politecnia na educação básica brasileira na perspectiva aqui mencionada, hoje em dia. Tais reflexões e análises permitiram concluir que as características atuais da sociedade brasileira dificultam a implementação da politecnia ou educação tecnológica em seu sentido original, uma vez que, dentre outros aspectos, a extrema desigualdade socioeconômica obriga grande parte dos filhos da classe trabalhadora a buscar a inserção no mundo do trabalho visando complementar o rendimento familiar, ou até mesmo a auto-sustentação, muito antes dos 18 anos de idade (Brasil, 2007, p. 17).

O documento Base do MEC da Educação Profissional Técnica de Nível Médio Integrada ao Ensino Médio assegura a impossibilidade de efetivação da Educação Profissional na forma Integrada nas bases universais e unitárias da politecnia em uma sociedade capitalista (Kuenzer; Garcia, 2008), pois “[... n não 
encontraria uma base material concreta de sustentação na sociedade brasileira atual, uma vez que esses jovens não podem 'se dar ao luxo' de esperar até os 20 anos ou mais para iniciar a trabalhar" (Brasil, 2007, p. 24).

Tais reflexões conduziram ao entendimento de que uma solução transitória e viável é um tipo de ensino médio que garanta a integralidade da educação básica, ou seja, que contemple o aprofundamento dos conhecimentos científicos produzidos e acumulados historicamente pela sociedade, como também objetivos adicionais de formação profissional numa perspectiva da integração dessas dimensões (Brasil, 2007, p. 24).

A Educação Profissional articulada ao Ensino Médio na forma Integrada e na perspectiva da politecnia, portanto, "[...] pode-se constituir em um processo de travessia para a materialização de uma educação tecnológica, politécnica" (Kuenzer; Garcia, 2008, p. 52).

Outro ponto importante a que o documento Base do MEC da Educação Profissional Técnica de Nível Médio Integrada ao Ensino Médio faz referência é com relação à falta de sentido e de significação do Ensino Médio, expressando a necessidade de uma identidade que venha a colaborar para a formação completa dos alunos (Brasil, 2007, p. 25).

O documento Base do MEC da Educação Profissional Técnica de Nível Médio Integrada ao Ensino Médio apresenta, ainda, cinco eixos que expressam as concepções e princípios da Educação Profissional na forma Integrada, descritos por Ramos (2006), ao analisar o conceito de integração, conforme mencionados. Os cinco eixos trabalhados no documento Base do MEC da Educação Profissional Técnica de Nível Médio Integrada ao Ensino Médio, tratam da formação humana integral; do trabalho, da ciência, da tecnologia e cultura como categorias indissociáveis da formação humana; o trabalho como princípio educativo; a pesquisa como princípio educativo; e a relação parte-totalidade na proposta curricular.

A formação humana integral concebe o Ensino Médio como parte inseparável da Educação Profissional em todos os campos onde se dá a preparação para o trabalho, ou seja, tanto nos processos produtivos quanto nos educativos. 
Isso significa enfocar o trabalho como princípio educativo, no sentido de superar a dicotomia trabalho manual/trabalho intelectual e incorporar a dimensão intelectual ao trabalho produtivo, isto é, formar trabalhadores atuantes.

O trabalho, a ciência, a tecnologia e a cultura são expressos no documento Base do MEC da Educação Profissional Técnica de Nível Médio Integrada ao Ensino Médio como categorias indissociáveis na formação humana, quando se trata da Educação Profissional articulada ao Ensino Médio na forma Integrada, conceituadas como:

a) Trabalho - "compreendermos como uma mediação de primeira ordem no processo de produção da existência e objetivação da vida humana. A dimensão ontológica do trabalho é, assim, o ponto de partida para a produção de conhecimentos e de cultura pelos grupos sociais".

Ciência - "é a parte do conhecimento melhor sistematizado e deliberadamente expresso na forma de conceitos representativos das relações determinadas e apreendidas da realidade considerada. O conhecimento de uma seção da realidade concreta ou a realidade concreta tematizada constitui os campos da ciência, as disciplinas científicas".

c) Tecnologia - "então, como mediação entre ciência (apreensão e desvelamento do real) e produção (intervenção no real)".

d) Cultura - "deve ser compreendida no seu sentido mais ampliado possível, ou seja, como a articulação entre o conjunto de representações e comportamentos e o processo dinâmico de socialização, constituindo o modo de vida de uma população determinada" (Kuenzer; Garcia, 2008, p. 54).

O trabalho como princípio educativo no documento Base do MEC da Educação Profissional Técnica de Nível Médio Integrada ao Ensino Médio é o fundamento que compreende a relação entre trabalho, ciência, tecnologia e cultura.

Considerar o trabalho como princípio educativo equivale dizer que o ser humano é produtor de sua realidade e, por isso, se apropria dela e pode transformá-la. Equivale dizer, ainda, que nós somos sujeitos de nossa história e de nossa realidade (Brasil, 2007, p. 45). 
No caso da Educação Profissional articulada ao Ensino Médio na forma Integrada, o que se pretende é que a Educação Profissional se torne parte inseparável do Ensino Médio, “[...] buscando enfocar o trabalho como princípio educativo, no sentido de superar a dicotomia trabalho manual trabalho intelectual, de incorporar a dimensão intelectual ao trabalho produtivo [...]" (Brasil, 2007, p. 41).

A proposta de um currículo integrado em quatro anos tenta assegurar o domínio dos conhecimentos que perfazem o itinerário cognitivo e formativo de um aluno-cidadão-trabalhador. Mas a superação da visão produtivista e mecanicista da educação e da escola somente poderá ser alcançada colocando o sujeito no centro da organização do trabalho educativo e pedagógico, e não mais o mercado de trabalho (Garcia, 2009, p. 64).

Dessa forma, confirma-se o compromisso de perseguir uma articulação e integração que seja [...] "orgânica entre trabalho como princípio educativo, a ciência e tecnologia como síntese de toda produção humana com seu meio, e a cultura, como síntese da formação geral e específica [...]” (Garcia, 2009, p. 63).

A relação parte-totalidade na proposta curricular no documento Base do MEC da Educação Profissional Técnica de Nível Médio Integrada ao Ensino Médio, discute a integração de conhecimentos gerais e específicos correspondentes à formação na Educação Profissional integrada, a partir da capacidade de relacionar parte e totalidade, em que

[...] cada fato ou conjunto de fatos, na sua essência, reflete toda a realidade com maior ou menor riqueza ou completude. Por essa razão, é possível que um fato deponha mais que um outro na explicação do real. Assim, a possibilidade de se conhecer a totalidade a partir das partes é dada pela possibilidade de se identificar os fatos ou conjunto de fatos que deponham mais sobre a essência do real; e, ainda, de distinguir o essencial do acessório, assim como o sentido objetivo dos fatos (Brasil, 2007, p. 50).

A última parte do documento Base do MEC da Educação Profissional Técnica de Nível Médio Integrada ao Ensino Médio apresenta alguns fundamentos e pressupostos para a construção de um Projeto Político Pedagógico para a Educação Profissional articulada ao Ensino Médio na forma Integrada, posto que 
O primeiro fundamento para a construção do projeto político pedagógico de qualquer escola é a sua construção coletiva. O projeto político pedagógico só existe de fato - não como um texto formal, ou uma "peça de ficção", mas com expressão viva de concepções, princípios, finalidades, objetivos e normas que unificam a comunidade escolar - se ele de fato pertencer a esse grupo; se o grupo se identificar com ele; se reconhecer nele (Brasil, 2007, p. 53).

Em síntese, buscamos evidenciar a importância da clareza conceitual da terminologia que trata das relações entre a Educação Profissional e o Ensino Médio, considerando que, em se tratando de educação, as palavras ou expressões em determinados contextos não podem ser utilizadas como sinônimos, a fim de não distorcer o seu sentido, além de imprimir um sentido teórico-ideológico que não corresponde com o real significado e aspecto a que se refere determinada Lei ou análise teórica.

\section{Referências}

ALVES, Ieda Maria. O conceito de neologia: da descrição lexical à planificação lingüística. Alfa, São Paulo: Departamento de Letras Clássicas e Vernáculas, Faculdade de Filosofia, Letras e Ciências Humanas - USP, 40: 11-16, 1996.

BRASIL. Decreto $n^{\circ} 5.154$, de 23 de julho de 2004. Regulamenta o $\S 2^{\circ}$ do art. 36 e os arts. 39 a 41 da Lei $\mathrm{n}^{\circ}$ 9.394, de 20 de dezembro de 1996, que estabelece as Diretrizes e Bases da Educação Nacional e dá outras providências. 2004.

. LDBEN: Lei de Diretrizes e Bases da Educação Nacional. Lei n ${ }^{\circ}$ 9394/96. Brasília: Câmara dos Deputados, 2001.

. MEC. Educação profissional técnica de nível médio integrada ao Ensino Médio. Brasília, 2007. (Documento Base).

BRYAN, Newton Antonio Paciulli. Educação, trabalho e tecnologia. 1992. Tese (Doutorado) - Unicamp, Campinas, 1992.

CIAVATTA, Maria. A formação integrada: a escola e o trabalho como lugares de memória e de identidade. In: FRIGOTTO, Gaudêncio; CIAVATTA, Maria; RAMOS, Marise (Orgs.). Ensino Médio integrado: concepções e contradições. São Paulo: Cortez, 2005. 
CIAVATTA, Maria. Formação integrada caminhos para a construção de uma escola para os que vivem do trabalho. In: SEED. O Ensino Médio integrado à educação profissional: concepções e construções a partir da implantação na Rede Pública Estadual do Paraná. Curitiba: SEED-PR, 2008.

CONFERÊNCIA quer Educação Profissional pública e integrada. $1^{\text {a }}$ Conferência Nacional de Educação Profissional e Tecnológica. Revista Ret-Sus, Brasília, novembro, 2006, p. 5-7, nov. 2006. Disponível em: <http://www.retsus.fiocruz.br/sites/default/files/ revista/pdf/retsus_revista_3.pdf $>$.

FAVORETO, Aparecida. Marxismo e educação no Brasil (1922-1935): o discurso do PCB e de seus intelectuais. 2008. Tese (Doutorado em Educação) - UFPR, Curitiba, 2008.

FRIGOTTO, Gaudêncio; CIAVATTA, Maria; RAMOS, Marise. Ensino Médio integrado: concepção e contradições. São Paulo: Cortez. 2005a.

. A política de educação profissional no governo Lula: um percurso histórico controvertido. Educ. Soc., Campinas, vol. 26, n. 92, p. 1.087-1.113, Especial, out. 2005b. Disponível em: <http://www.cedes.unicamp.br>.

FRIGOTTO, Gaudêncio; CIAVATTA, Maria. Educação Básica no Brasil na década de 1990: subordinação ativa e consentida à lógica do mercado. Revista Educação e Sociedade, Campinas, v. 24, n. 82, 2003.

Ensino Médio: ciência, cultura e trabalho. Brasília: MEC; Semtec, 2004.

FRIGOTTO, Gaudêncio. A interdisciplinaridade como necessidade e como problema nas ciências sociais. In: JANTSCH, Ari Paulo; BIANCHETTI, Lucídio (Orgs.). A interdisciplinaridade: para além da filosofia do sujeito. Petrópolis: Vozes, 1995.

GARCIA, Sandra Regina de Oliveira. A Educação Profissional Integrada ao Ensino Médio no Paraná: avanços e desafios. Tese de Doutorado. 2009.

GRIEBELER, Janice Rosangela Cardoso. A política de educação profissional articulada ao Ensino Médio na forma integrada no Paraná: uma análise da implementação no Colégio Estadual João Manoel Mondrone no município de Medianeira - Paraná (20032010). 2013. Dissertação (Mestrado) - Unioeste, Cascavel, PR, 2013.

GUILBERT, Louis. La créativité. Paris: Larousse, 1975.

KUENZER, Acácia Zenaida; GARCIA. Sandra Regina de Oliveira. Os Fundamentos políticos e Pedagógicos que norteiam a Implantação da Educação Profissional Integrada ao Ensino Médio. In: $\mathrm{O}$ ensino médio integrado à educação profissional: concepções e construções a partir da implantação na Rede Pública Estadual do Paraná. Curitiba: SEED - PR, 2008. 
KUENZER, Acácia Zeneida. Educação, linguagens e tecnologias: as mudanças no mundo do trabalho e as relações com o conhecimento e método. In: Cultura, linguagem e subjetividade no ensinar e aprender. Rio de Janeiro: DP\&A, 2000.

LIMA FILHO, Domingos Leite. Impactos das recentes políticas públicas de educação e formação de trabalhadores: desescolarização e empresariamento da educação profissional. Perspectiva, Florianópolis, v. 20, n. 2, p. 269-301, jul./dez. 2002.

MANACORDA, Mario Alighiero. Marx e a pedagogia moderna. Trad. Newton Ramos de Oliveira. São Paulo: Cortez; Autores Associados, 1991.

OLIVEIRA, Ramon de. Possibilidades do Ensino Médio integrado diante do financiamento público da educação. Educação e Pesquisa, São Paulo, v. 35, n. 1, p. 051-066, jan./abr. 2009.

PARANÁ. Superintendência da Educação. Departamento de Educação Profissional. Educação Profissional no Paraná: fundamentos políticos e pedagógicos. Curitiba: SEED, 2005a.

SEED; SUED. Reformulação curricular no Estado do Paraná - um trabalho coletivo. Yvelise Freitas de Souza Arco Verde, 2005b.

RAMOS, Marise Nogueira. Concepção do ensino médio integrado á educação profissional. In: O Ensino Médio integrado à educação profissional: concepções e construções a partir da implantação na Rede Pública Estadual do Paraná. Curitiba, SEED/PR: 2008.

. O ensino médio ao longo do século XX: um projeto inacabado. Boletim da Educação, Movimento dos Trabalhadores Rurais Sem Terra-MST, n.11, p. 51-60, set. 2006.

RIBEIRO, Cláudio Gomes. Conferência quer educação profissional pública e integrada. Conferência Nacional de Educação Profissional e Tecnológica. Revista Ret-Sus, Brasília, p. 5-7, nov. 2006. Disponível em: <http://www.retsus.fiocruz.br/sites/default/files/revista/ pdf/retsus_revista_3.pdf $>$.

SAVIANI, Demerval. O choque teórico da politecnia. Trabalho, educação e saúde. Rio de Janeiro: EPSJV; Fiocruz, n.1, p.131-152, 2003. Disponível em: <http://www.revista. epsjv.fiocruz.br/upload/revistas/r41.pdf>.

Recebido em: 12/6/2015

Aceito em: 29/7/2016 